\title{
The infection of microvascular endothelial cells with ExoU-producing Pseudomonas aeruginosa triggers the release of von Willebrand factor and platelet adhesion
}

\author{
Carla Freitas ${ }^{1}$, Maria-Cristina Assis², Alessandra Mattos Saliba1', Veronica Maria Morandi \\ Camila Castro Figueiredo ${ }^{3}$, Mirian Pereira ${ }^{4}$, Maria-Cristina Plotkowski ${ }^{1 /+}$ \\ 1'Departamento de Microbiologia e Imunologia ${ }^{3}$ Departamento de Biologia Celular, Universidade do Estado do Rio de Janeiro, \\ Rio de Janeiro, RJ, Brasil ²Departamento de Ciências Biológicas e da Saúde, Centro Universitário Estadual da Zona Oeste, \\ Rio de Janeiro, RJ, Brasil ${ }^{4}$ Departamento de Ultra-Estrutura e Biologia Celular-Fiocruz, Rio de Janeiro, RJ, Brasil
}

An increased plasma concentration of von Willebrand factor $(v W F)$ is detected in individuals with many infectious diseases and is accepted as a marker of endothelium activation and prothrombotic condition. To determine whether ExoU, a Pseudomonas aeruginosa cytotoxin with proinflammatory activity, enhances the release of $v W F$, microvascular endothelial cells were infected with the ExoU-producing PA103 P. aeruginosa strain or an exoU-deficient mutant. Significantly increased $v W F$ concentrations were detected in conditioned medium and subendothelial extracellular matrix from cultures infected with the wild-type bacteria, as determined by enzyme-linked immunoassays. PA103-infected cells also released higher concentrations of procoagulant microparticles containing increased amounts of membrane-associated $v W F$, as determined by flow cytometric analyses of cell culture supernatants. Both flow cytometry and confocal microscopy showed that increased amounts of $v W F$ were associated with cytoplasmic membranes from cells infected with the ExoU-producing bacteria. PA103-infected cultures exposed to platelet suspensions exhibited increased percentages of cells with platelet adhesion. Because no modulation of the vWF mRNA levels was detected by reverse transcription-polymerase chain reaction assays in PA103-infected cells, ExoU is likely to have induced the release of $v W F$ from cytoplasmic stores rather than $v W F$ gene transcription. Such release is likely to modify the thromboresistance of microvascular endothelial cells.

Key words: Pseudomonas aeruginosa - von Willebrand factor - prothrombotic activity - microparticles

Pseudomonas aeruginosa is a major agent of sepsis, a clinical syndrome characterised by the infection-triggered activation of the inflammatory and coagulation systems and by endothelial dysfunction (Esmon 2005).

The endothelium usually functions as an antithrombotic surface and is critical for maintaining normal vascular homeostasis (Schouten et al. 2008). However, under conditions of sepsis, endothelial cells are activated to secrete and express surface procoagulant molecules such as tissue factor (TF) and von Willebrand factor (vWF) (Vallet \& Wiel 2001). Activated endothelial cells also release increased amounts of procoagulant microparticles, which are small membrane-derived vesicles shed by cells following activation or during apoptosis under a variety of pathophysiological circumstances (Martinez et al. 2005). Microparticle membranes exhibit an antigen repertoire that is representative of the cell membranes from which they are derived, except for the loss of phospholipid asymmetry. Consequently, microparticle membranes contain anionic phosphatidylserine in their exoplasmic leaflet,

Financial support: CNPq, FAPERJ

CF was supported by a scholarship from CNPq.

+ Corresponding author: crisplot@yahoo.com.br

Received 8 November 2011

Accepted 9 April 2012 enabling the assembly of clotting enzyme complexes and the generation of thrombin. Hardly detectable in the peripheral blood of healthy individuals, elevated levels of circulating procoagulant microparticles are often associated with thrombotic potential. The expression of TF (del Conde et al. 2005) and vWF (Jimenez et al. 2003) on endothelial microparticle membranes further contributes to their potential role in hemostasis dysfunction.

VWF is a large multimeric glycoprotein that is synthesised in endothelial cells and megakaryocytes and plays a pivotal role in hemostatic plug formation and thrombosis (Ruggeri 2007). The main functions of vWF are to mediate the adhesion of platelets to sites of vascular injury and to act as a bridge molecule for platelet aggregation, promoting the interaction of specific binding sites with the platelet surface receptors GP Iba and aIIbb-3 integrin (Ruggeri 2007, Varga-Szabo et al. 2008). High-molecular-weight vWF multimers, the most important factors for physiological platelet function, are released from endothelial cells towards both the lumen and the subendothelial matrix (Ruggeri 2003, 2007). Increased concentrations of circulating vWF are detected in individuals with many pathologic conditions, including acute infectious diseases (Pottinger et al. 1989, , Kayal et al. 1998), and are generally accepted as a marker of endothelium activation/dysfunction (Vischer et al. 2000).

One of the most important $P$. aeruginosa virulence factors is ExoU, a cytotoxin with phospholipase $\mathrm{A}_{2}$ activity (Sato et al. 2003, Engel \& Balachandran 2009). Pre- 
vious studies from our group have highlighted the ability of ExoU to elicit a potent inflammatory response in microvascular endothelial cells (Saliba et al. 2005) and to enhance the release of soluble ICAM-1 from P. aeruginosa-infected endothelial cells (Lins et al. 2010), demonstrating the toxin's ability to induce endothelial activation/dysfunction (Gando et al. 2005). In the present study, we investigated whether ExoU would promote the release of vWF from endothelial cells, thereby contributing to enhanced platelet adhesion/aggregation and potentially to the generation of prothrombotic conditions.

\section{SUBJECTS, MATERIALS AND METHODS}

Bacterial strains and culture conditions - P. aeruginosa PA103 and the ExoU-deficient PA103_exoU mutant (Saliba et al. 2005) were used throughout this study. Bacteria were grown in Luria-Bertani broth at $37^{\circ} \mathrm{C}$ for 16-18 h, harvested by centrifugation and resuspended in MCDB 131 cell culture medium (Sigma-Aldrich) supplemented with $10 \%$ foetal calf serum, $10 \mathrm{ng} \mathrm{mL}^{-1}$ EGF (Sigma-Aldrich), $1 \mu \mathrm{g} \mathrm{mL}^{-1}$ hydrocortisone (SigmaAldrich) and glutamine (complete culture medium).

Cell culture and infection - Cells from the human microvascular endothelial cell line-1 (HMEC-1) (Ades et al. 1992) were cultured in complete MCDB-131 culture medium for $48 \mathrm{~h}$. Bacterial suspensions were added to the cell cultures at a multiplicity of infection of approximately 100 bacteria per cell and centrifuged $(1,000 \mathrm{~g}$ for $10 \mathrm{~min}$ ) to promote close contact between the bacteria and host cells (Saliba et al. 2005). Control cultures were exposed to culture medium alone. After incubation for $1 \mathrm{~h}$ at $37^{\circ} \mathrm{C}$, cells were incubated with culture medium containing $300 \mu \mathrm{g} / \mathrm{mL}$ gentamicin for different lengths of time to reduce the bacterial challenge and to assess the host response at later time points (Saliba et al. 2005, Lins et al. 2010).

Detection of released $\nu W F$ - To detect vWF released into the cell supernatant, cells cultured in 6-well plates ( 4.5 x $10^{5}$ cells/well) were infected for $1 \mathrm{~h}$, rinsed and incubated with gentamicin-containing culture medium for $72 \mathrm{~h}$ (Ribeiro et al. 1995). The conditioned media from control and infected cultures were then concentrated 20-fold with a Speed Vac Plus (Savant) and the vWF concentration was assayed in duplicate by ELISA using purified rabbit anti-human vWF and a horseradish peroxidase-conjugated anti-vWF secondary antibody (Dako), as previously described (Bonnefoy et al. 2001). A standard curve was constructed from serial dilutions of normal pooled human plasma, assuming a vWF concentration of $1 \mathrm{unit} / \mathrm{mL}$.

To detect the released vWF that was incorporated into the subendothelial matrix, cells were cultured in 96-well dishes $\left(0.3 \times 10^{4}\right.$ cells/well), infected for $1 \mathrm{~h}$ (or not infected) and treated with gentamicin-containing medium for $72 \mathrm{~h}$. Cells were then washed with phosphate buffered saline (PBS) and treated for 20 min with PBS containing $0.1 \mathrm{M} \mathrm{NH}_{4} \mathrm{OH}$ and $0.1 \%$ Triton X-100 to expose the native subendothelial matrix (Bonnefoy et al. 2001). After washing, the wells of the microtitre plate were fixed with $4 \%$ paraformaldehyde, treated with $1 \%$ bovine serum albumin (BSA) in PBS and exposed to the anti-vWF-horse- radish peroxidase conjugate. The concentrations of $\mathrm{vWF}$ in the supernatant and the subendothelial matrix were normalised and reported in $\mathrm{U} / \mathrm{mL}$ released by $10^{5}$ cells.

Detection of $v W F$-expressing microparticles in cell supernatants - Cells were infected for $1 \mathrm{~h}$ and then treated with gentamicin-containing medium. Control cells were treated similarly with antibiotic-containing medium. After incubation at $37^{\circ} \mathrm{C}$ for $19 \mathrm{~h}$, the incubation media were cleared of cell debris by centrifugation $(5,000 \mathrm{~g}$ for $15 \mathrm{~min}$ ) and then centrifuged at $17,500 \mathrm{~g}$ for $30 \mathrm{~min}$ at $15^{\circ} \mathrm{C}$ (Plotkowski et al. 2008). Sedimented microparticles were washed and treated for $30 \mathrm{~min}$ at room temperature (RT) with annexin V-Alexa Fluor 647 complexes (Invitrogen) to identify surface phosphatidylserine residues. After washing, microparticles were suspended in PBS containing $1 \%$ BSA and analysed by flow cytometry. The region corresponding to shed microparticles was defined in sideangle light scatter vs. fluorescent intensity dot plot representations using $0.5 \mu \mathrm{m}$ and $0.9 \mu \mathrm{m}$ fluorescent beads (Megamix) as a reference, according to the manufacturer's instructions. Because ExoU cytotoxicity leads to the partial death of PA103-infected cultured cells, the numbers of viable cells in the PA103 and PA103_exoU-infected culture wells and in the control uninfected culture wells were determined in parallel after the $1 \mathrm{~h}$ infection period. The microparticle concentrations detected in the cell culture supernatants were then normalised and reported as microparticles shed by $10^{5}$ cells. In other assays, before treatment with the annexin V complex, sedimented microparticles were incubated with rabbit anti-human vWF for $1 \mathrm{~h}$ and then incubated for $30 \mathrm{~min}$ at RT with goat anti-rabbit IgG-FITC. After washing, microparticles were analysed by flow cytometry. The results were expressed as a "vWF-expression index" as described (Leytin et al. 2000) and this value was obtained by the following formula: percentage of vWF-expressing microparticles $\mathrm{x}$ median microparticle fluorescence intensity.

Detection of cell-associated $v W F$ - Two different approaches were used to determine whether any portion of the secreted vWF remained associated with the cultured cells: flow cytometry and confocal microscopy analysis of nonpermeabilized cells. For the flow cytometry analysis, cells were infected for $1 \mathrm{~h}$, treated with antibiotic-containing medium for an additional $5 \mathrm{~h}$, washed with PBS to remove all microparticles that were associated with cell membranes, detached from the wells by trypsinisation and fixed in 4\% paraformaldehyde in PBS containing $4 \%$ sucrose for $20 \mathrm{~min}$. After washing with PBS, cells were treated with a rabbit anti-human vWF antibody for $1 \mathrm{~h}$ at $4^{\circ} \mathrm{C}$, washed and incubated with a goat anti-rabbit IgG-FITC complex (Santa Cruz Biotechnology). The cells were then washed again and suspended in PBS containing $1 \%$ BSA. At least 5,000 cells were analysed by flow cytometry. Control uninfected cells were processed similarly. The results were expressed as a "vWF-expression index", calculated as described above.

For the confocal microscopy analysis, cells were grown on glass coverslips, infected (or not infected) for $1 \mathrm{~h}$, treated with antibiotic-containing medium for additional $5 \mathrm{~h}$, washed to remove microparticles associated with cell 
membranes, fixed with $4 \%$ paraformaldehyde and stained with anti-vWF antibody and goat anti-rabbit IgG-Cy3 complex (Zymed). In some assays, cells were subsequently stained with phalloidin-FITC (Sigma-Aldrich), washed and incubated with Topro (Invitrogen) for $5 \mathrm{~min}$. Coverslips were mounted on glass slides and observed under a Zeiss LSM 510 Meta confocal microscope.

Detection of $v W F$ mRNA by reverse transcriptionpolymerase chain reaction (RT-PCR) - Total RNA was isolated from uninfected (control) HMEC-1 cells or cells infected for 1 or $3 \mathrm{~h}$ using the Qiagen RNeasy kit. cDNA was synthesised from the total RNA by RT with the SuperScript ${ }^{\mathrm{TM}}$ First-Strand Synthesis System for RT-PCR (Invitrogen). The isolated cDNA was subjected to PCR under the following conditions: denaturation at $95^{\circ} \mathrm{C}$ for 2 min, 33 (vWF) or 23 (B-actin) cycles of denaturation at $95^{\circ} \mathrm{C}$ for $45 \mathrm{sec}$, annealing at $50^{\circ} \mathrm{C}$ for 45 $\mathrm{sec}$ and extension at $72^{\circ} \mathrm{C}$ for $45 \mathrm{sec}$, and an additional extension step of $5 \mathrm{~min}$ at $72^{\circ} \mathrm{C}$ after the last cycle. The primers used in the reactions were 5'-AGTTCATGGAGGAGGTGATTCAGC-3' (vWF sense), 5'-AGCCATCCAGGAGAAGGATCACG-3' (vWF antisense), 5'-CCTCGCCTTTGCCGATCC-3' (B-actin sense) and 5'-GGATCTTCATGAGGTAGTCAGTC-3' (B-actin antisense). PCR products were subjected to electrophoresis in a $1 \%$ agarose gel and densitometry was performed using Lab Image software (Kaplan GmbH, Germany).

Platelet adhesion to P. aeruginosa-infected cells - To investigate the relationship between increased vWF release by PA103-infected cells and enhanced platelet adhesion, cells cultured on glass coverslips were infected for $1 \mathrm{~h}$ and then treated with gentamicin-containing culture medium for additional $5 \mathrm{~h}$. In parallel, human blood was collected in ACD anticoagulant solution $(130 \mathrm{mM}$ citric acid, $153 \mathrm{mM}$ citrate trisodium and $111 \mathrm{mM}$ glucose; $\mathrm{pH}$ 6.5) containing $\mathrm{PGE}_{1}$ at $1 \mathrm{U} / \mathrm{mL}$ and centrifuged at $250 \mathrm{~g}$ for $8 \mathrm{~min}$. The resulting platelet-rich plasma was centrifuged at $1,500 \mathrm{~g}$ for $10 \mathrm{~min}$. Sedimented platelets were washed in platelet buffer $(36 \mathrm{mM}$ citric acid, $5 \mathrm{mM}$ glucose, $5 \mathrm{mM} \mathrm{KCl}, 2 \mathrm{mM} \mathrm{CaCl}, 1 \mathrm{mM} \mathrm{MgCl}_{2}$ and 103 $\mathrm{mM} \mathrm{NaCl} ; \mathrm{pH}$ 6.4) and resuspended at a concentration of $1.0 \times 10^{7}$ platelets $/ \mathrm{mL}$. Infected and control uninfected endothelial cells were then incubated with the platelet suspension for $30 \mathrm{~min}$ at RT. In other assays, platelet suspensions were perfused over endothelial cells for $5 \mathrm{~min}$ $(10 \mathrm{~mL} / \mathrm{min})$ with a peristaltic pump (Pump-1, Pharmacia Biotech). Cells were then washed, fixed for $20 \mathrm{~min}$ with $4 \%$ paraformaldehyde in PBS containing 4\% sucrose and stained with May-Grunwald-Giemsa stain. Coverslips were mounted on glass slides and examined with a Zeiss Axioplan optical microscope. The percentage of cells with adherent platelets present in at least 10 different microscopic fields was determined in two different assays, both of which were carried out in duplicate.

Statistical analysis - The results were expressed as the means \pm standard error of the means of data obtained in at least three different experiments. Significant differences between groups were determined with one-way analysis of variance followed by Dunnett's or Bonferroni's multiple comparisons post-test. Statistical significance was set at a $\mathrm{p}$ value of $<0.05$.

\section{RESULTS}

ExoU enhanced the release of $\nu W F$ and $\nu W F$-bearing microparticles from microvascular endothelial cells - As shown in Fig. 1, the concentrations of vWF in both the cell culture supernatant (Fig. 1A) and subendothelial matrix (Fig. 1B) of endothelial cells infected with the ExoU-producing bacterial strain were significantly higher than those in control cultures or in cultures infected with the exoU-deficient mutant.

ExoU similarly enhanced the release of microparticles containing anionic phosphatidylserine in their exoplasmic leaflet, as revealed by their reactivity with the annexin V-FITC complex (Fig. 2B, D). More importantly, the vWF expression indices for microparticles shed after PA103 infection were significantly higher than those for microparticles shed by control cells or by cells infected with the PA103_exoU mutant (Fig. 2C, E).

$P A 103$-infected cells exhibited increased $\nu W F$ expression - Studies have shown that vWF multimers released from endothelial cells are anchored to the endothelial surface in the form of structures that are capable of binding platelets before being cleaved by plasma metalloproteases
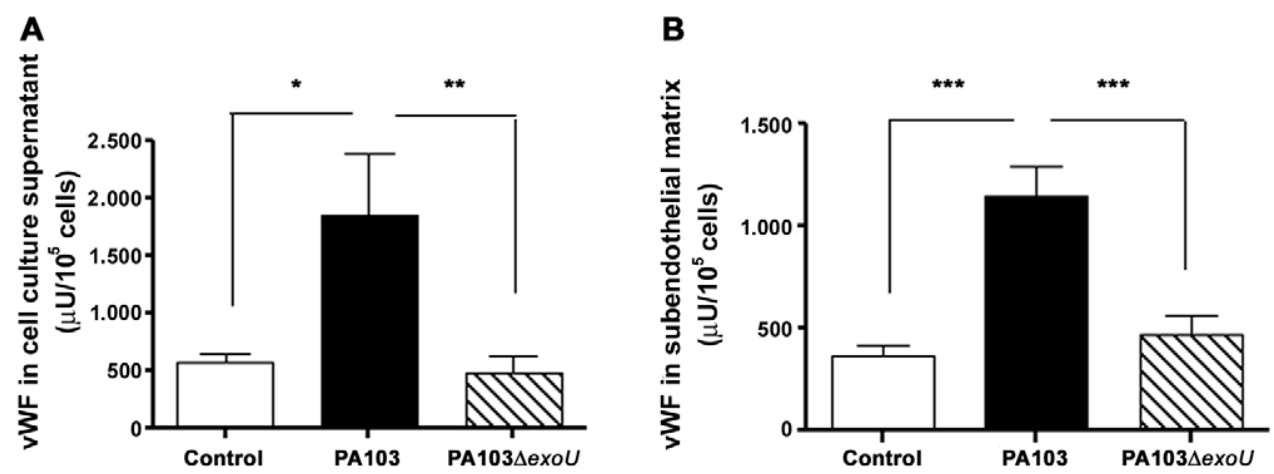

Fig. 1: concentration of von Willebrand factor (VWF) in cell culture supernatant (A) and subendothelial matrix (B) from control uninfected and infected endothelial cells detected by ELISA analysis. Data represent means and standard error of the means of the results from five assays carried out in duplicate (A) or eight assays carried out in quadruplicate (B). *: $\mathrm{p}<0.05 ; * *$ : $<0.01 ; * *$ : $\mathrm{p}<0.001$. 
(Dong et al. 2002). To investigate whether PA103-infected cells harbour increased amounts of surface-associated vWF, nonpermeabilized control and infected cells were treated with an anti-vWF antibody and submitted to flow cytometry and immunocytochemistry analyses.

As shown in Fig. 3, the vWF-expression index of cells infected with the wild-type bacteria was significantly higher than those of uninfected control cells and cells infected with the mutant bacteria. Confocal microscopy analyses confirmed the increased expression of vWF on the surface of PA103-infected cells (Fig. 4).

Because ExoU is a phospholipase, we wondered whether the increased staining of PA103-infected cells with the anti-vWF antibody, detected by both flow cytometry and confocal microscopy, may have been caused by the permeabilization of cell membranes by the toxin; this permeabilization would enable the antivWF antibody to penetrate infected cells and stain vWF stored in Weibel Palade bodies. To address this question, nonpermeabilized fixed control and infected cells were treated with phalloidin-FITC, which labels cytoplasmic actin and with the anti-vWF antibody and then examined by confocal microscopy. Control and infected cells were equally poorly labelled with phalloidin-FITC (data not shown), thereby ruling out the false-positive staining of PA103-infected cells.

ExoU did not modulate the level of VWF mRNA expressed by infected cells - To determine whether the increased vWF expression and release from PA103-infected cells depended on the modulation of vWF mRNA

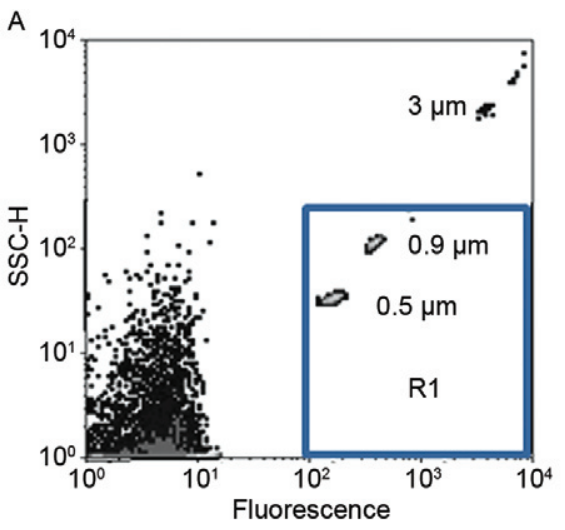

B
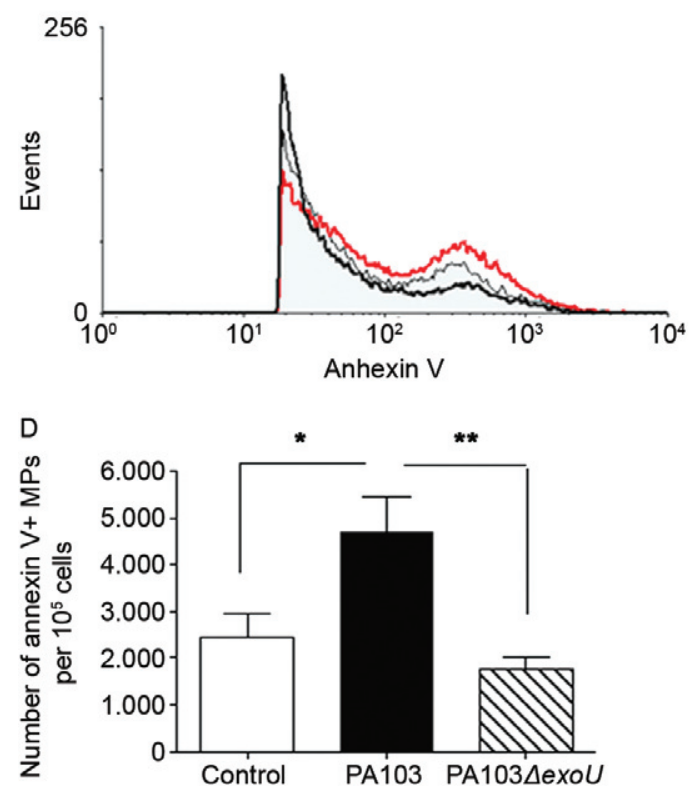

C
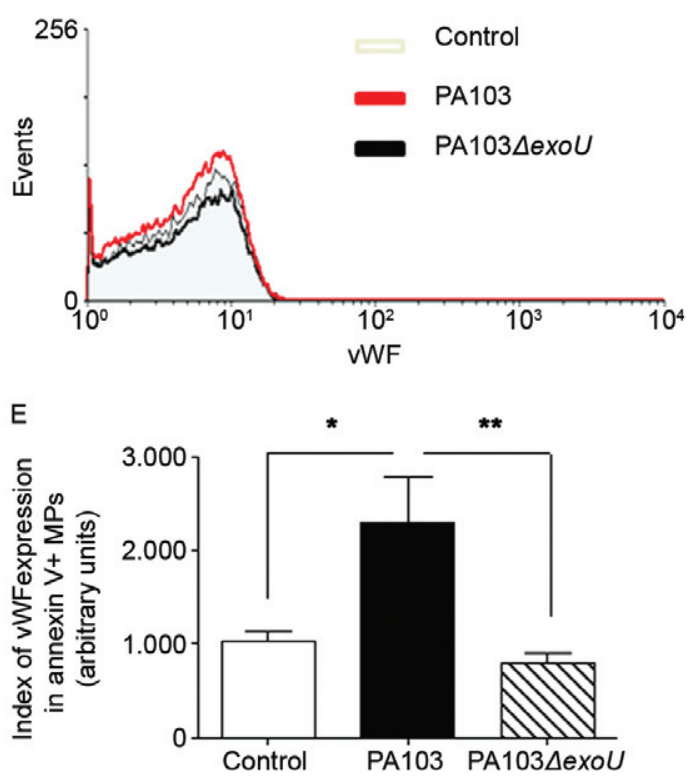

Fig. 2: release of microparticles (MPs) by control and infected endothelial cells detected by flow cytometry analysis. A: dot plot histogram showing the distribution of fluorescent beads used for the flow cytometer setting before analysis of MPs in region defined as R1; B: representative histogram showing increased number of annexin V-labelled MPs released by PA103-infected cells; C: representative histogram showing increased number of annexin V positive MPs expressing von Willebrand factor (vWF) released by PA103-infected cells; D: mean number and standard error of the means (SEM) of MPs released by $10^{5}$ cells, as determined in three assays carried out in triplicate; E: index of vWF expression by annexin V positive MPs, obtained with the formula: percentage of vWF-expressing MPs x median of MP fluorescence intensity. Data represent means and SEM of the results from three assays carried out in triplicate. SSC-H: side scatter complexity histogram; $*$ : $<0,05 ; * *$ : $<<0.01$. 
levels, we performed RT-PCR assays. No difference in mRNA levels was detected between control and $P$. aeruginosa-infected cells (data not shown).

ExoU enhanced platelet adhesion to infected endothelial cells - To evaluate whether the ExoU-induced release of vWF favoured platelet adhesion to endothelial cells, platelet suspensions were either incubated with or perfused over HMEC-1 cells cultured on glass coverslips. In PA103-infected cultures incubated with platelets under static conditions, the percentage of cells with adherent platelets was significantly higher than that in control cultures or in cultures infected with the exoU mutant (Fig. 5A). More interestingly, PA103-infected cultures exposed to platelets under flow conditions for only $5 \mathrm{~min}$ also exhibited a significantly higher percentage of cells with adherent platelets (Fig. 5B). No significant difference in the percentage of cells with adherent platelets was observed between cultures infected with the bacterial mutant and control cultures.

\section{DISCUSSION}

Endothelial cells usually provide an ideal surface for blood flow by inhibiting platelet adhesion and the initiation of blood clotting. In contrast, platelets adhere avidly to activated or injured endothelium via several adhesion molecules that are expressed on these cells (Wu \& Thiagarajan 1996, Varga-Szabo et al. 2008). Because $P$. aeruginosa ExoU may directly damage endothelial cells (Saliba et al. 2006), we investigated whether this toxin might alter the thromboresistant phenotype of the microvascular endothelium and promote platelet adhesion.

We demonstrated that ExoU enhanced the release of vWF into the endothelial cell culture supernatant and subendothelial matrix. One explanation for this phenomenon might be that arachidonic acid released by PA103-infected cells, as previously reported by our group (Saliba et al. 2005), enhances the fusion of Weibel Palade bodies with the endothelial plasma membrane, resulting in vWF exocytosis (Connell et al. 2007, Darios et al. 2007). A second potential explanation is that vWF release may have resulted from ExoU-induced endothelial cell lysis. Because a similar injury of endothelial

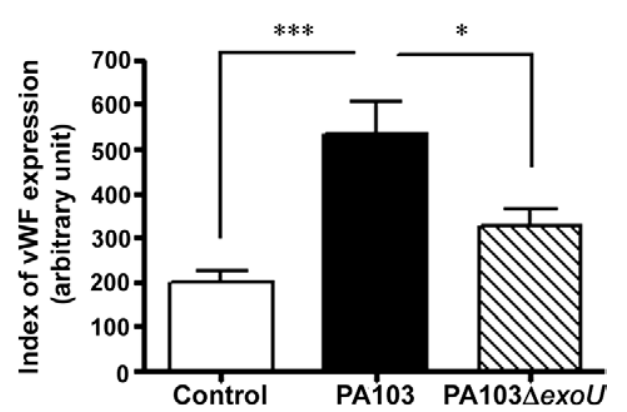

Fig. 3: index of cell-associated von Willebrand factor (vWF) in control uninfected and infected cells, obtained with the formula: percentage of vWF-expressing cells x median of cell fluorescence intensity. Data represent means and standard error of the means of the results from four assays carried out in triplicate. *: $\mathrm{p}<0,05 ; * * * \mathrm{p}<0.001$. cells is likely to occur in vivo, the vWF release reported here is likely relevant; the immobilisation of vWF released towards the lumen of blood vessels on exposed subendothelial matrix is considered to be the predominant mechanism that initiates platelet response in areas of vascular injury (Ruggeri 2003).

A proposed model for the regulation of $\mathrm{vWF}$ release is that upon stimulation, ultra-large vWF multimers are released and immediately anchored to the surface of endothelial cells via binding to P-selectin. These multimers are then stretched by fluid shear stress into an open conformation and cleaved by the metalloproteinase ADAMTS-13 into fragments of various sizes that are detected in the plasma of healthy individuals (Dong et al. 2002, Padilla et al. 2004). Because cultured endothelial cells are not exposed to fluid shear, uncleaved ultra-large $\mathrm{vWF}$ is likely to remain anchored to cell membranes. Such anchorage would explain both the increased expression of surface-associated vWF, as detected by confocal microscopy and the increased adhesion of nonstimulated platelets to PA103-infected cells.

The physiological relevance of vWF-mediated platelet adhesion to endothelial cells, rather than to sites of endothelial injury, has been highlighted by in vivo studies showing that resting platelets adhere to intact mouse mesenteric venules treated with a secretagogue of Weibel Palade bodies through a vWF-dependent and P-selectin-independent mechanism (Sporn et al. 1986, Andre et al. 2000). Although platelets recruited to the endothelium may release proinflammatory cytokines and modulate leukocyte function, thereby contributing to local defence mechanisms, they can also initiate deleterious thrombotic events.

Another finding from our study that may have in vivo relevance is the enhanced release of vWF-expressing microparticles from PA103-infected cells. Microparticles released from activated or apoptotic endothelial cells participate in platelet aggregation owing to the presence of functional adhesive glycoproteins in the plasma membranes. These glycoproteins bind to the A1 domain of immobilised and soluble vWF (Reininger 2008). In addition, high percentages of endothelial-derived microparticles (EMP) express ultra-large vWF multimers (Jimenez et al. 2003, Jy et al. 2005, Othman et al. 2007). The multimeric size of vWF is important for its function because lower molecular weight multimers show less binding to platelets and to collagen (Doucet-de Bruine et al. 1978, Santoro et al. 1983). In a study on the interaction between EMP and platelets, Jy et al. (2005) highlighted the importance of the large molecular weight vWF expressed by EMP. In the presence of ristocetin, EMP induced the aggregation of up to $95 \%$ of platelets and EMP-induced platelet aggregates were more stable than those induced by free soluble vWF. These results further support the procoagulant properties of endothelial microparticles.

In conclusion, this report describes the effects of endothelial cell infection with the ExoU-producing PA103 $P$. aeruginosa, showing that ExoU enhanced $\mathrm{vWF}$ release and that at least a portion of the released $\mathrm{vWF}$ remained associated with the cell surface. ExoU also enhanced the 
release of prothrombotic vWF-bearing microparticles and platelet adhesion to infected cells. Although it is tempting to conclude that there is a cause-effect relationship between the increased expression of cell-associated vWF and increased platelet adhesion to PA103-infected cells, further studies are necessary to prove that vWF is involved in platelet-endothelial cell association.

In recent years, our laboratory has made progress in understanding the contribution of ExoU to the pathogenesis of $P$. aeruginosa infections. We first demonstrated that ExoU may induce a procoagulant activity in airway epithelial cells, resulting from the upregulated expression of TF and the increased release of tissue factorpositive microparticles (Plotkowski et al. 2008). More recently, Machado et al. (2010) demonstrated that ExoU can induce vascular hyper-permeability, platelet acti- vation and thrombus formation in the lungs and renal microvasculature of mice with experimental $P$. aeruginosa pneumosepsis; these authors also observed an antifibrinolytic environment in mice airways secondary to the induction of enhanced plasminogen activator inhibitor-1 production (Machado et al. 2011). These results, as well as those from the present report, demonstrate the potential of ExoU to induce a prothrombotic state in host organisms.

\section{ACKNOWLEDGEMENTS}

To Maria Angélica P da Silva and Pedro Paulo de Abreu Manso, for her technical assistance, Dr Marcelo Santiago (Instituto de Biofísica Carlos Chagas Filho, UFRJ), for his support with confocal microscopy, and to PDTIS, for use of its facilities.
Control

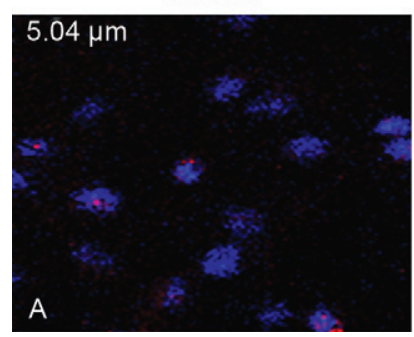

PA103

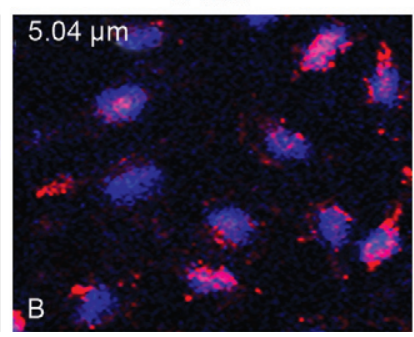

PA103 $\Delta$ exoU

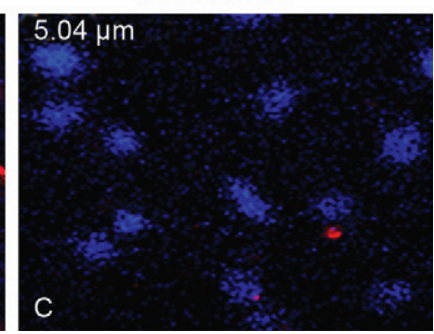

Fig. 4: confocal microscopy detection of von Willebrand factor (labelled in red) at the surface of nonpermeabilized paraformaldehyde-fixed control (A), PA103 (B) and PA103_exoU-infected endothelial cells (C). Cell nuclei appear labelled in blue.

\section{A}

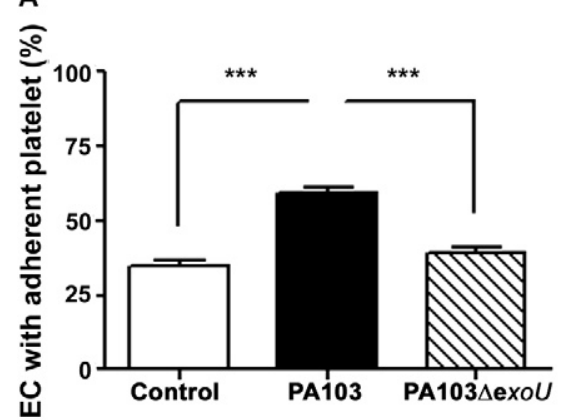

C

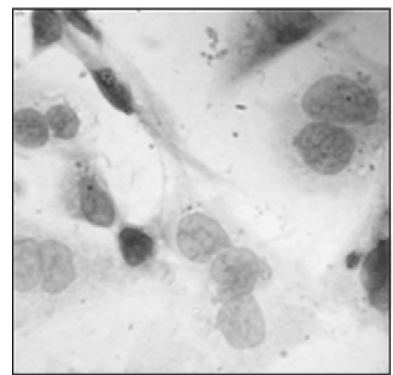

B

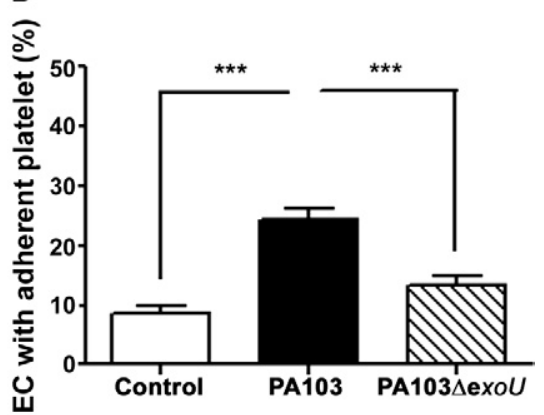

PA103

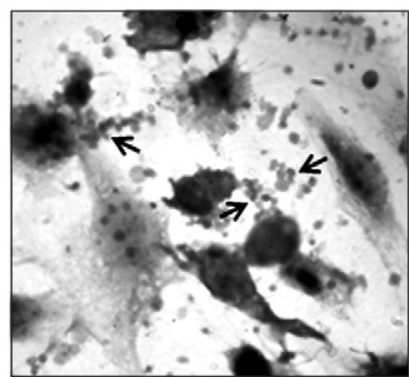

$\operatorname{PA103} \Delta \mathrm{exOU}$

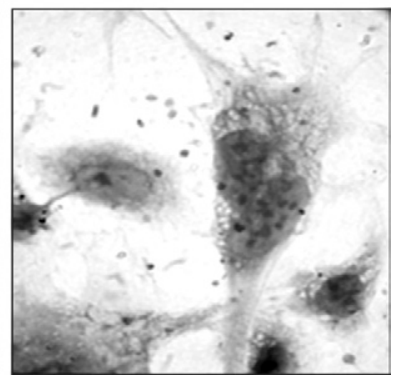

Fig. 5: platelet adhesion to control and infected endothelial cells. Percentage of cells with adherent platelets after cell incubation with platelet suspensions under static (A) and perfusion (B) conditions. Data represent means and standard error of the means from results of two experiments carried out in triplicate. C: light micrographs of control and infected endothelial cells exposed to platelet suspensions under static conditions. Arrows point to platelet aggregates. Asterisks mean $\mathrm{p}<0.001$. 


\section{REFERENCES}

Ades EW, Candal FJ, Swerlick RA, George VG, Summers S, Bosse DC, Lawley TJ 1992. Establishment of an immortalized human microvascular endothelial cell line. J Invest Dermatol 99: 683-690.

Andre P, Denis CV, Ware J, Saffaripour S, Hynes RO, Ruggeri ZM, Wagner DD 2000. Platelets adhere to and translocate on von Willebrand factor presented by endothelium in stimulated veins. Blood 96: 3322-3328.

Bonnefoy A, Harsfalvi J, Pfliegler G, Fauvel-Lafève F, Legrand C 2001. The subendothelium of the HMEC-1 cell line supports thrombus formation in the absence of von Willebrand factor and collagen types I, III and VI. Thromb Haemos 85: 552-559.

Connell E, Darios F, Broersen K, Gatsby N, Peak-Chew S, Rickman C, Davletov B 2007. Mechanism of arachidonic acid action on syntaxin-Munc18. EMBO Rep 8: 414-419.

Darios F, Connell E, Davletov B 2007. Phospholipases and fatty acid signalling in exocytosis. J Physiol 585: 699-704.

del Conde I, Shrimpton CN, Thiagarajan P, López JA 2005. Tissuefactor-bearing microvesicles arise from rafts and fuse with activated platelets to initiate coagulation. Blood 106: 1604-1611.

Dong J, Moake JL, Nolasco L, Bernardo A, Arceneaux W, Shrimpton CN, Schade AJ, McIntire LV, Fujikawa K, Lopez JA 2002. ADAMTS-13 rapidly cleaves newly secreted ultralarge von Willebrand factor multimers on the endothelial surface under flowing conditions. Blood 100: 4033-4039.

Doucet-de Bruine MHM, Sixma JJ, Over J, Beeser-Visser NH 1978. Heterogeneity of factor VIII: characterization of forms of factor VIII binding to platelets in the presence of ristocetin. J Lab Clin Med 92: 96-107.

Engel J, Balachandran P 2009. Role of Pseudomonas aeruginosa type III effectors in disease. Curr Opin Microbiol 12: 61-66.

Esmon CT 2005. The interactions between inflammation and coagulation. Br J Haematol 131: 417-430.

Gando S, Kameue T, Matsuda N, Hayakawa M, Hoshino H, Kato H 2005. Serial changes in neutrophil-endothelial activation markers during the course of sepsis associated with disseminated intravascular coagulation. Thromb Res 116: 91-100.

Jimenez JJ, Jy W, Mauro LM, Horstman LL, Soderland C, Ahn YS 2003. Endothelial microparticles released in thrombotic thrombocytopenic purpura express von Willebrand factor and markers of endothelial activation. Br J Haematol 123: 896-902.

Jy W, Jimenez JJ, Mauro LM, Horstman LL, Cheng P, Ahn ER, Bidot CJ, Ahn YS 2005. Endothelial microparticles induce formation of platelet aggregates via a von Willebrand factor/ristocetin dependent pathway, rendering them resistant to dissociation. J Thromb Haemost 3: 1301-1308.

Kayal S, Jais JP, Aguini N, Chaudiere J, Labrousse J 1998. Elevated circulating E-selectin, intercellular adhesion molecule 1 and von Willebrand factor in patients with severe infection. Am J Respir Crit Care Med 157: 776-784.

Leytin V, Mody M, Semple JW, Freedman J 2000. Flow cytometric parameters for characterizing platelet activation. Biochem Bioph Res Comm 269: 85-90.

Lins RX, de Assis MC, Mallet de Lima CD, Freitas C, Plotkowski MC, Saliba AM 2010. ExoU modulates soluble and membranebound ICAM-1 in Pseudomonas aeruginosa-infected endothelial cells. Microb Infect 12: 154-161.

Machado GB, de Assis MC, Leão R, Saliba AM, Silva MC, Suassuna JH, de Oliveira AV, Plotkowski MC 2010. Exou-induced vascular hyperpermeability and platelet activation in the course of experimental Pseudomonas aeruginosa pneumosepsis. Shock 33: $315-321$.

Machado GB, de Oliveira AV, Saliba AM, de Lima CD, Suassuna JH, Plotkowski MC 2011. Pseudomonas aeruginosa toxin ExoU in- duces a PAF-dependent impairment of alveolar fibrin turnover secondary to enhanced activation of coagulation and increased expression of plasminogen activator inhibitor-1 in the course of mice pneumosepsis. Respir Res 5: 104.

Martinez MC, Tesse A, Zobairi F, Andriantsitohaina R 2005. Shed microparticles from circulating and vascular cells in regulating vascular function. Am J Physiol Heart Circ Physiol 288: H1004-H1009.

Othman M, Labelle A, Mazzetti I, Elbatarny HS, Lillicrap D 2007. Adenovirus-induced thrombocytopenia: the role of von Willebrand factor and P-selectin in mediating accelerated platelet clearance. Blood 109: 2832-2839.

Padilla A, Moake JL, Bernardo A 2004. P-selectin anchors newly released ultralarge von Willebrand factor multimers to the endothelial cell surface. Blood 103: 2150-2156.

Plotkowski MC, Feliciano LFP, Machado GBS, Cunha Jr LG, Freitas C, Saliba AM, Assis MC 2008. ExoU-induced procoagulant activity in Pseudomonas aeruginosa-infected airway cells. Eur Respir J 32: 1591-1598.

Pottinger BE, Read CR, Paleolog EM, Higgins PG, Pearson JD 1989. von Willebrand factor is an acute phase reactant in man. Thromb Res 15: 387-394.

Reininger AJ 2008. VWF attributes impact on thrombus formation. Thromb Res 122 (Suppl. 4): S9-S13.

Ribeiro MJA, Phillips DJ, Benson JM, Evatt BL, Ades EW, Hooper WC 1995. Hemostatic properties of the SV-40 transfected human microvascular endothelial cell line (HMEC-1). Thromb Res 79: 153-161.

Ruggeri ZM 2003. von Willebrand factor, platelets and endothelial cell interactions. J Throm Haemost 1: 1335-1342.

Ruggeri ZM 2007. The role of von Willebrand factor in thrombus formation. Thromb Res 120 (Suppl. 1): S5-S9.

Saliba AM, Assis MC, Nishi R, Raymond B, Marques EA, Lopes UG, Touqui L, Plotkowski MC 2006. Implications of oxidative stress in the cytotoxicity of Pseudomonas aeruginosa ExoU. Microb Infect 8: 450-459.

Saliba AM, Nascimento DO, Silva MCA, Assis MC, Gayer CRM, Raymond B, Coelho MGP, Marques EA, Touqui L, Albano RM, Lopes UG, Paiva DD, Bozza PT, Plotkowski MC 2005. Eicosanoid-mediated proinflammatory activity of Pseudomonas aeruginosa ExoU. Cell Microbiol 7: 1811-1822.

Santoro SA 1983. Preferential binding of high molecular weight forms of von Willebrand factor to fibrillar collagen. Biochim Biophys Acta 756: 123-126.

Sato H, Frank DW, Hillard CJ, Feix JB, Pankhaniya RR, Moriyama $\mathrm{K}$, Finck-Barbançon V, Buchaklian A, Lei M, Long RM, Wiener-Kronish J, Sawa T 2003. The mechanism of action of the Pseudomonas aeruginosa-encoded type III cytotoxin, ExoU. EMBO J 22: 2959-2969.

Schouten M, Wiersinga WJ, Levi M, van der Poll T 2008. Inflammation, endothelium and coagulation in sepsis. J Leukoc Biol 83: 1-10.

Sporn LA, Marder VJ, Wagner DD 1986. Inducible secretion of large biologically potent von Willebrand factor multimers. Cell 46: 185-190.

Vallet B, Wiel E 2001. Endothelial cell dysfunction and coagulation. Crit Care Med 29 (Suppl. 7): S36-S41.

Varga-Szabo D, Pleines I, Nieswandt B 2008. Cell adhesion mechanisms in platelet. Arterioscler Thromb Vasc Biol 28: 403-412.

Vischer UM, Barthm H, Wollheim CB 2000. Patterns of cytoskeletal remodeling in cultured endothelial cells regulated von Willebrand factor secretion is associated with agonist-specific. Arterioscler Thromb Vasc Biol 20: 883-891.

Wu KK, Thiagarajan P 1996. Role of endothelium in thrombosis and hemostasis. Annu Rev Med 47: 315-331. 